\title{
Flow cell for operando X-ray photon-in-photon-out studies on photo-electrochemical thin film devices
}

P. Jäker ${ }^{1,2}$, D. Aegeter ${ }^{1}$, T. Kyburz ${ }^{1}$, R. Städler ${ }^{1}$, R. Fonjallaz ${ }^{1}$, B. Detlefs ${ }^{3}$, D. Koziej ${ }^{1,2 *}$

${ }^{1}$ ETH Zurich, Department of Materials, Laboratory for Multifunctional Materials, Vladimir-Prelog-Weg 5, 8093 Zurich, Switzerland

${ }^{2}$ University of Hamburg, Institutes of Nanostructure and Solid State Physics, Center for Hybrid Nanostructures, Luruper Chaussee149, 22607 Hamburg, Germany

${ }^{3}$ European Synchrotron Radiation Facility, 71 avenue des Martyrs, CS 40220, 38043, Grenoble,France 


\section{Abstract}

Photo-electro-chemical (PEC) water splitting represents a promising technology towards an artificial photosynthetic device but many fundamental electronic processes, which govern long-term stability and energetics are not well understood. X-ray absorption spectroscopy (XAS), particularly its high energy resolution fluorescence-detected (HERFD) mode, emerges as a powerful tool to study photoexcited charge carrier behavior under operating conditions.

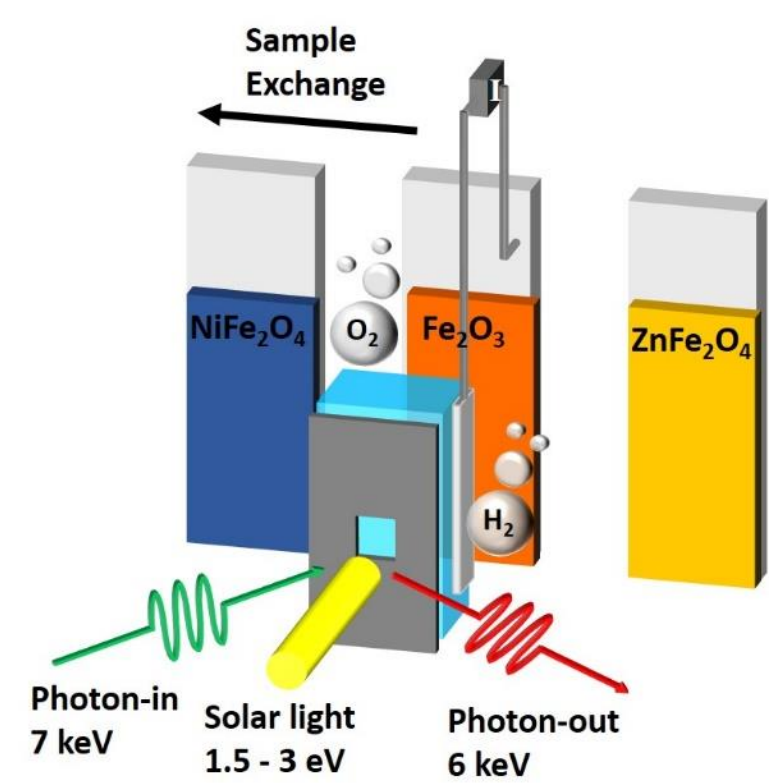

The established thin film device architecture of PEC cells provides a well-defined measurement geometry, but it puts many constraints on conducting operando XAS experiments. So far, operando cells have not been developed that enable to concurrently measure highly intense X-ray fluorescence and photo-electrochemical current without experimental artifacts caused by $\mathrm{O}_{2}$ and $\mathrm{H}_{2}$ bubbles formation. Moreover, we are missing a standardized thin film exchange procedure.

Here, we address and overcome the instrumental limitations for operando HERFD-XAS to investigate photo-and electrochemical thin film devices. Our cell establishes a measurement routine that will provide experimental access to a broader scientific community, particularly due to the ease of sample exchange. Our operando photo-electro-chemical cell is optimized for the HERFD-XAS geometry and we demonstrate its operation by collecting high-resolution Fe K-edge spectra of hematite $\left(\boldsymbol{\alpha}-\mathrm{Fe}_{2} \mathrm{O}_{3}\right)$ and ferrite thin film $\left(\mathrm{MFe}_{2} \mathrm{O}_{4}, \mathrm{M}=\mathrm{Zn}, \mathrm{Ni}\right)$ photoelectrodes during water oxidation. 


\section{- INTRODUCTION}

Photo- and electrochemical thin film devices are ubiquitous in current energy conversion technologies such as solar cells or electrolyzer. Its principal geometry enables precise control and determination of surface area, thickness and optical path lengths, which are fundamental to determine related physical properties of materials like absorption coefficient and conductivity and device performance metrics such as current density. Photo-electro-chemical (PEC) water splitting represents a promising thin film based application integrating photovoltaic and electrosynthetic functions within a single device to produce hydrogen as energy storage medium. ${ }^{1,2}$ Overarching research goals on the path towards commercialization are the realization of conversion efficiencies competitive with solar thermal water splitting or wind and solar power driven electrolyzers and long term device stability $(\sim 10-20$ years $) .^{3-5}$ Due to the topical complexity a common research strategy relies on explorative and iterative materials engineering. ${ }^{6-8} \mathrm{We}$ observe continously raising energy conversion efficiencies, but underlying photoelectrochemical processes still remain unexplored and thus we are lacking a more fundamental understanding of this technology. ${ }^{9}$ In PEC devices semiconductor liquid electrolyte interfaces are modelled analogous to Mott-Schottky contacts, which physical parameters are not assumed to be modified during operation. ${ }^{10}$ However, based on recent results for $\mathrm{BiVO}_{4}$, an n-type semiconductor photoanode, photocorrosive processes alter the materials chemical and morphological state during operation. ${ }^{11,12} \mathrm{X}$-ray absorption spectroscopy (XAS) is particularly appealing to study materials and devices under working conditions due to its high penetration depth and chemical selectivity. ${ }^{13,14}$ Moreover, in HERFD-XAS the energy resolution is enhanced by wavelength-dispersive detection of the X-ray fluorescence, giving access to subtle spectral feature variations such as observed in $\mathrm{CO}_{2}$ sensing. ${ }^{15}$ Operando experiments provide new insights such as 
an electrochemically induced surface layer ${ }^{16}$ or light-excited charge $\operatorname{transfer}^{17}$ and are becoming common to analyze electrochemical (electrocatalysis, batteries) ${ }^{18,19}$ and photochemical processes ${ }^{20}$. In these areas, essential device requirements such as electrical connection and light transparency do not interfere and simplify operando cell design. However, to study photo-electro-chemical processes both qualities have to be ensured simultaneously increasing the complexity of the cell design.

The few existing examples of operando XAS photo-electro-chemical studies interpret their findings as photoexcited charge transfer, either between atoms of two different materials as in the case of $\mathrm{Nb}: \mathrm{SrTiO}_{3} / \mathrm{MnO}_{\mathrm{x}}{ }^{21}$ and $\mathrm{Fe}_{2} \mathrm{O}_{3} / \mathrm{IrO}_{\mathrm{x}}{ }^{22}$ or within the same material as for $\mathrm{Fe}_{2} \mathrm{O}_{3}{ }^{23}$. In semiconductor photoelectrochemistry the challenge is to disentangle effects caused by the electrical bias and light absorption. Photoinduced phenomena are often studied using pump-probe techniques utilizing coherent monochromatic laser light. ${ }^{24}$ However, lasers high irradiance leads to numerous excited states, that are only probed in narrow spectral regions and might not be representative. Here, we are interested to study processes under realistic conditions utilitzing standard PEC devices architecture under full solar spectral illumination. To this end, the cell requires to host three electrodes to record electro-chemical current-voltage (I-V) signals and shall be designed to minimize solar light and X-ray attentuation. Current cell versions are limited by electrochemical noise ${ }^{21}$ or uncessarily high X-ray beam attentuation ${ }^{25}$. A further challenge is a complicated and irreversible sample exchange mechanism. For instance, depositing samples directly onto the cell 's window material, such as $\mathrm{Si}_{3} \mathrm{~N}_{4}$, transforms the costly part into a non-reusable one. ${ }^{23}$ We address the above mentioned shortcomings by realizing an operando cell, that enables to record highquality X-ray absorption spectra and to control current-voltage responses with low electrochemical noise. 
Switching thin film materials for sequential operando measurements is achieved in a very straightforward manner and enables reproducible experiments on series of samples. 


\section{RESULTS \& DISCUSSION}

\section{Operando cell design and assembly}

The underlying idea was to conceive a measurement cell, that provides consistent instrumental conditions, such as electrical connection and optical pathlength to explore, in a reproducable way, aqueous photo-and electrochemical processes occuring in thin film materials. The cell is dedicated for the use of conductive substrates such as fluorine-doped tin oxide (FTO) or indium tin oxide (ITO). It consists of six main parts which are front, back, fastening and transducer as well as $\mathrm{Si} / \mathrm{Si}_{3} \mathrm{~N}_{4}$-chip and photoelectrode as shown in Figure $1 \mathrm{a}-\mathrm{b}$. The front part accomodates in- and out-flow connections, electrode slots, a mold to insert the photoelectrode and the $\mathrm{Si} / \mathrm{Si}_{3} \mathrm{~N}_{4}$ chip as well as the aperture. The front part is joined with the back part, which contains a threaded fastening. The transducer transfers the exerted pressure and reduces shear forces onto the photoelectrode and $\mathrm{Si} / \mathrm{Si}_{3} \mathrm{~N}_{4}$ chip. This architecture employs only mechanical forces for sealing and hence allows a rapid sample exchange. This decisive feature decouples sample preparation, i.e. the applied thin film deposition technique, from cell assembly and allows to probe thin films fabricated from physical and chemical methods. Additionally, the straightforward mechanical photoelectrode insertion reduces the necessarily needed and often costly $\mathrm{Si} / \mathrm{Si}_{3} \mathrm{~N}_{4}$ chip to a single and reusable quantity. This is significantly more practical and inexpensive opposed to approaches where the sample is directly deposited onto the $\mathrm{Si}_{3} \mathrm{~N}_{4}$ membranes. ${ }^{23}$ The sealing between the thin film and Si-chip is realized by compression and therefore it has to be ensured that films have even surfaces. The cell is designed to operate in a typical three electrode configuration, in which the photoelectrode acts as the working electrode (WE) and its operating voltage is measured against a reference electrode (RE). A commercially available $\mathrm{Ag} / \mathrm{AgCl}$-electrode is chosen as RE which is encapsulated by a glass body that is inserted into the cell's RE- 
slot and sealed with a pair of O-rings as shown in Figure $1 \mathrm{~b}$. The counter electrode (CE), a Pt-wire, compensates the current generated at the WE and is tightened by a rubber conus and teflon tape. Principally, the RE and CE can be exchanged for measurements in electrolytes of different $\mathrm{pH}$-values or for anodically more active electrodes, respectively. The cell's front and back parts (dark grey) shown in Figure $1 \mathrm{a}$ are manufactured by computer numerical control milling from poly(methylmethacrylat) (PMMA). PMMA provides the necessary water resistivity to perform aqueous photoelectrochemical experiments and transparency, which allows to spot possible electrolyte leakage and to follow the wetting behavior of the three electrodes. Especially the RE requires uniform electrolyte coverage of the porous frit, undisturbed by gas bubbles, to ensure a stable reference potential. Electrolyte is supplied from syringe pumps via chemically resistant poly(tetrafluorethylene) (PTFE) tubings. They are connected to the cell's flow system via flangeless tube end fittings that ensure reliable, leakage free operation. The cell's channels have a diameter of $500 \mu \mathrm{m}$ and are sufficiently wide for flow rates up to $5 \mathrm{~mL} \mathrm{~min}^{-1}$. A flow cell is advantageous to a static one as a constant temperature is maintained during solar and X-ray beam irradiation preventing possible radiation damage. Additionally, continuously refreshing the electrolyte, which is consumed during water splitting, ensures a stable $\mathrm{pH}$ and moreover, releases the gaseous endproducts, $\mathrm{H}_{2}$ and $\mathrm{O}_{2}$. For mechanical stability and precise positioning, a M5 thread is implemented into the cell's front part to mount the cell onto the beamline's sample stage. The technical drawings are provided as SI. 

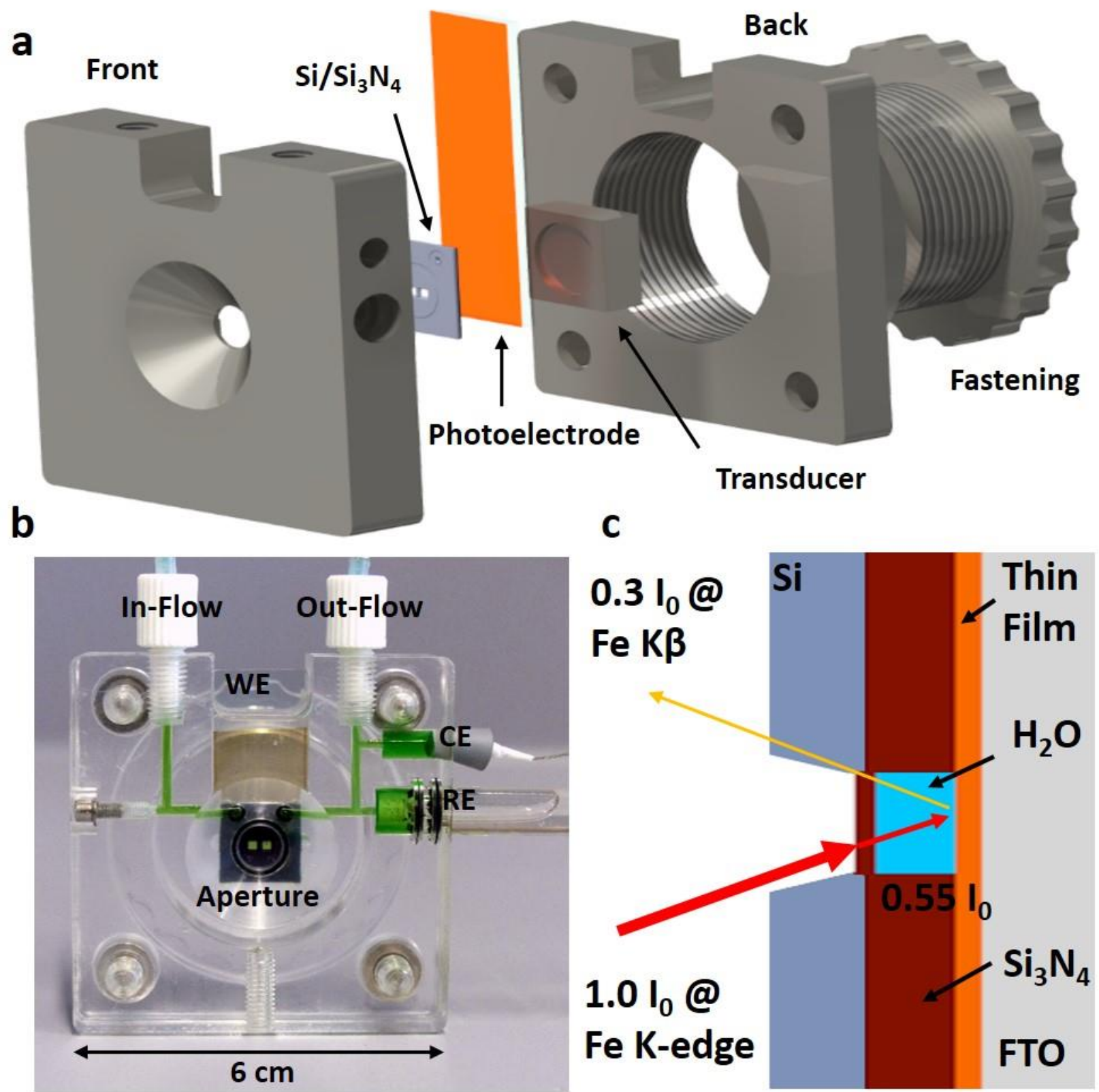

Figure 1. The schematics of the cell used for operando hard X-ray photon-in photon-out spectroscopy studies under photo-electro-chemical water splitting conditions. (a) The exploded view highlights the most important components such as the front, transducer, back and fastening parts (dark grey), $\mathrm{Si} / \mathrm{Si}_{3} \mathrm{~N}_{4}$ chip as optical aperture for UV-Vis and X-ray beam (light grey) and photoelectrode (orange). (b) Photograph of the cell showing the three electrodes configuration: thin-film based photoelectrode (WE), platinum wire (CE) and $\mathrm{Ag} / \mathrm{AgCl}$ 
electrode (RE). A green-colored solution is used to visualize the electrolyte path inside the cell. (c) A schematic illustrating the optical path in a photon-in-photon-out process. The X-ray intensities incident on the sample and on the detector are given after passing $500 \mathrm{~nm}$ of $\mathrm{Si}_{3} \mathrm{~N}_{4}$ and $400 \mu \mathrm{m}$ of water for the Fe K-edge upon absorption (photon-in at $7112 \mathrm{eV}$ ) and for the $\mathrm{Fe} \mathrm{K} \beta_{1,3}$ line upon emission (photon-out at $7059 \mathrm{eV}$ ).

Central in photon-in-photon-out spectroscopy is to minimize absorption losses for both the incident and fluorescent X-rays as schematically shown in Figure 1c. Consequently, a very thin optical window material that consists of low atomic number $(\mathrm{Z})$ elements is required which is also transparent in the visible region. Thus, we employed two $500 \mathrm{~nm}$ thin $\mathrm{Si}_{3} \mathrm{~N}_{4}$ membranes as a windows, which are thick enough to provide the necessary mechanical stability to withstand the water pressure. They are embedded into a $400 \mu \mathrm{m}$ thick Si-chip which contains a fluidic channel that connects the fluid ports to the central 2-window area. The fluidic channels are defined by a $400 \mu \mathrm{m}$ deep spacer, integral to the chip structure. The spacer layer is made of a multilayer of $\mathrm{Si}$ and $\mathrm{SiN}_{\mathrm{x}}$ films. Although an even thinner electrolyte layer would minimize absorption effects, it would also introduce electrochemical mass transfer and flow rate limitations. Taking transmission losses into account ${ }^{26}$, we estimated that this setup retains $30 \%$ of the original intensity (Figure 1c) on detecting Fe K $\beta$ fluoresence $(7059 \mathrm{eV})$ while exciting at the Fe K-edge $(7112 \mathrm{eV})$, as shown in detail in Section 1 of the SI and visualized in Figure S1.

\section{Metal oxide photoelectrodes}

We select hematite and transition metal ferrites photoelectrodes for the applicability tests of an operando HERFD-XAS cell. We choose hematite, because it is one of the most characterized metal-oxide photoanode for water oxidation and served as model compound for in situXAS and XPS studies. ${ }^{23,27}$ Transition metal ferrites of the composition $\mathrm{MFe}_{2} \mathrm{O}_{4}(\mathrm{M}=\mathrm{Mn}, \mathrm{Co}, \mathrm{Ni} \& \mathrm{Zn})$ are ternary oxides that offer to tune the optoelectronic properties by varying the non-iron cation. ${ }^{28}$ Similary to hematite, they have shown chemical stability for hours of 
operation $^{29}$ and are promising photoelectrochemical materials with an optical band-gap range between $1.5 \mathrm{eV}$ and $1.9 \mathrm{eV}$, that enable theoretical, assuming 100\% incident-photon-to-current (IPCE) conversion, current densities from $29 \mathrm{~mA} \mathrm{~cm}^{-2}$ to $18 \mathrm{~mA} \mathrm{~cm}^{-2} \cdot{ }^{30}$ Among the transition metal ferrites nanoparticles that are accessable via the benzyl alcohol route ${ }^{31,32} \mathrm{MnFe}_{2} \mathrm{O}_{4}$ and $\mathrm{CoFe}_{2} \mathrm{O}_{4}$ demonstrated only marginal photocurrents and thus we exclusively focus on $\mathrm{ZnFe}_{2} \mathrm{O}_{4}$ and $\mathrm{NiFe}_{2} \mathrm{O}_{4}$ with $\mathrm{Fe}_{2} \mathrm{O}_{3}$ as the model photoelectrodes for operando HERFD-XAS studies, see Figure S2 for corresponding photocurrent measurements. Additional information on crystal structure and thin film morphology including its thickness can be found in SI section 2 Figure S3-S6.

\section{Photoelectrochemical measurements}

Inferring mechanistic information from X-ray spectral changes relies on the controllable and predictable behavior of the applied stimulus i.e. electrical potential and solar illumination and their measurable effect. Thus, we compare the operando cell to a commonly used standard laboratory photoelectrochemical cell..$^{33}$ Conducting photoelectrochemical experiments on the same material but in two different cells should reveal apparatus related differences. Our analysis focuses on the working electrode potential regulation and photocurrent measurements.

Therefore, we compared constant potential or chronoamperometric measurements of $\mathrm{Fe}_{2} \mathrm{O}_{3}$ photoanodes in our operando cell with $0.031 \mathrm{~cm}^{2}$ illuminated area versus our laboratory cell with $0.28 \mathrm{~cm}^{2}$ illuminated area as shown in Figure 2. The measurement protocol includes a stepwise potential increase after $360 \mathrm{~s}$ during which dark and illuminated periods alternate every $60 \mathrm{~s}$. The applied potential follows the set potential from 1.0 to $1.6 \mathrm{~V}$ vs RHE in steps of $0.2 \mathrm{~V}$ and demonstrates the successful voltage regulation (Figure 2, top). In the dark, recorded current densities are $0.001-0.005^{\circ} \mathrm{mA}^{\circ} \mathrm{cm}^{-2}$ for both cells in the applied potential range of $1.0 \mathrm{~V}$ to $1.4 \mathrm{~V}$ indicating no significant faradaic processes. At $1.6 \mathrm{~V}$ the applied potential starts to match the kinetic overpotential causing water oxidation with a rate up to $0.07 \mathrm{~mA}^{\circ} \mathrm{cm}^{-2}$ in the operando cell, which is about $0.05^{\circ} \mathrm{mA}^{\circ} \mathrm{cm}^{-2}(\sim 3.5$ times $)$ greater 
than for the laboratory cell with $0.02 \mathrm{~mA} \mathrm{~cm}^{-2}$. However, contrary to the laboratory cell which provides equally sized dark and illuminated areas on the photoelectrode, the operando cell's total electrolyte exposed geometric surface area towards the photoelectrode amounts to $0.172 \mathrm{~cm}^{2}$ (Figure S7) and is about 5.5 times larger than the illuminated area. Therefore, renormalization corresponding to a current density reduction by a factor of 5.5 to $0.013 \mathrm{~mA} \mathrm{~cm}^{-2}$ reveals current densities in the laboratory cell to be 1.6 times higher. During illumination and under potentials of $1.0 \mathrm{~V}$ vs RHE values stabilize at $0.25 \mathrm{~mA} \mathrm{~cm}^{-2}$ and are doubled to $0.5 \mathrm{~mA} \mathrm{~cm} \mathrm{~cm}^{-2}$ upon potential increase to $1.2 \mathrm{~V}$. Within this voltage window the photocurrent densities recorded in our operando cell match very well the values obtained in the laboratory cell. However, by increasing the applied potential further to $1.4 \mathrm{~V}$ and 1.6 V the operando cell delivers slightly higher steady-state photocurrent densities of about $0.90 \mathrm{~mA} \mathrm{~cm}^{-2}$ and $1.05 \mathrm{~mA} \mathrm{~cm}^{-2}$, respectively than the laboratory cell with $0.75 \mathrm{~mA} \mathrm{~cm}^{-2}$ and $0.95 \mathrm{~mA} \mathrm{~cm}^{-2}$, respectively. Whether in the dark or under illumination, recorded current densities deviate at higher applied voltages for which the effect of potentially different solution resistances would be amplified. Further contributing factors are related to variations during sample preparation ${ }^{34}$ or potential sample modification under operation ${ }^{35,36}$, both itself promising research topics but difficult aspects to control due to the material's physical complexity. However, electrolyte mass transfer behavior will clearly be affected as the cell's geometry is modified and liquid flow is actively driven compared to the static laboratory cell. Up to now, we considered steady-state values varying maximally about 1.6 times but observe 7-8 times variation in transient peak current densities upon triggering solar illumination or a potential step (Figure S8). Such transients are common in chronoamperometric experiments in the dark ${ }^{37}$ and under illumination ${ }^{38,39}$ and are explained via non-faradaic charging processes, both within the semiconductor and electrolyte, or via electrolyte diffusion after initial near-electrode depletion. As the same transient behavior is observed for measurements on a different material, namely $\mathrm{NiFe}_{2} \mathrm{O}_{4}$ (Figure S9), the underlying cause might be cell geometry and flow. 


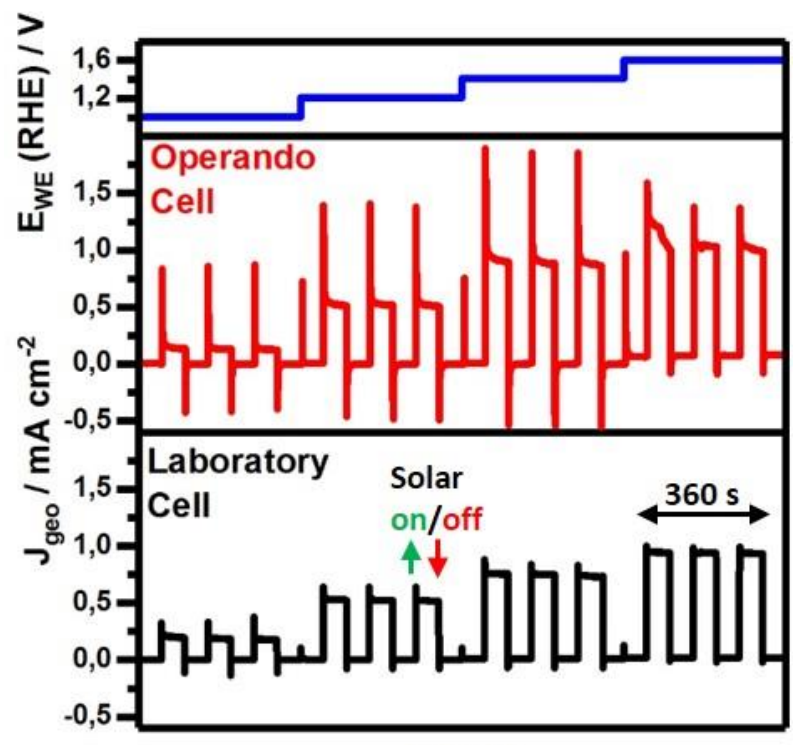

time / s

Figure 2. Comparison of photocurrent densities of the $\mathrm{Fe}_{2} \mathrm{O}_{3}$ photoanodes under constantly applied potentials (blue) recorded in the operando flow cell (red) and laboratory cell (black). Photocurrent measurements show that the operando cell generates low noise, and the photocurrent densities, normalized to the geometrically illuminated area, are similar to those obtained in the laboratory cell.

The previous discussion is a starting point to understand the operando cell's photoelectrochemical characteristics. Future, more quantitative work will rely on comprehending its current-voltage behavior in detail. However, the near steady-state conditions are reached within seconds after the external stimulus (light or bias) and can be reproduced multiple times for extended periods (Figure 5) allowing repeatable XAS scans to be averaged, as discussed in the next section. Therefore, we conclude that photoelectrochemical conditions are maintained that closely resemble laboratory testing conditions and allow to qualitatively investigate associated phenomena of thin film photoelectrodes using X-ray absorption spectroscopy.

In addition, the operation in continuous flow provides significant advantages. We maintain a constant temperature and thus can exclude thermally induced effects due to UV-Vis and X-ray absorption as opposed to 
photo-electro-chemical effects. In the same instance, we avoid the formation of gaseous bubbles that can adsorb onto the photo-electrodes surface and decrease the active surface area, which would lower the photocurrent. Additionally, as gas droplets are of lower density than water, they enhance transmission of both UV-Vis light and X-rays. Frequent density variations along the X-ray beam path lead to abrupt, spike-like intensity fluctuations and generate unreliable data. Consequently, by minimizing gas accumulation our operando cell raises the amount of high-quality valid data.

\section{Data quality under operando conditions}

Assuming the energy resolution is unaffected by measuring under operando conditions the signal-to-noise ratio (SNR) is an important parameter characterizing the data quality. Here, the SNR is described as quotient of the arithmetic mean $\mu$ and the standard deviation $\sigma^{40,41}$ and is proportional to the square root of the signal obtained under identical conditions assuming Gaussian noise. ${ }^{42,43}$ To calculate the SNR the spectral region from $7180 \mathrm{eV}$ to $7184 \mathrm{eV}$ was chosen, in which the measured intensity was almost constant. To assess the additional time required to compensate for absorption losses caused by the electrolyte and the $\mathrm{Si}_{3} \mathrm{~N}_{4}$ windows, we estimated a signal detection yield of $30 \%$ upon Fe K-edge absorption and K $\beta$-fluorescence (Figure 1 c, SI Section 1 and Figure S1), which corresponds to a SNR decrease by a factor of 1.8 .

We compare two Fe K-edge scans on an approximately 50-80 nm thin $\mathrm{Fe}_{2} \mathrm{O}_{3}$ film under ex situ (Figure 3, left black) and operando conditions (Figure 3, left red). The intensity of the Fe K-edge spectrum measured in operando is attenuated by a factor of 12 thus leading to a detection yield of $8.33 \%$. 

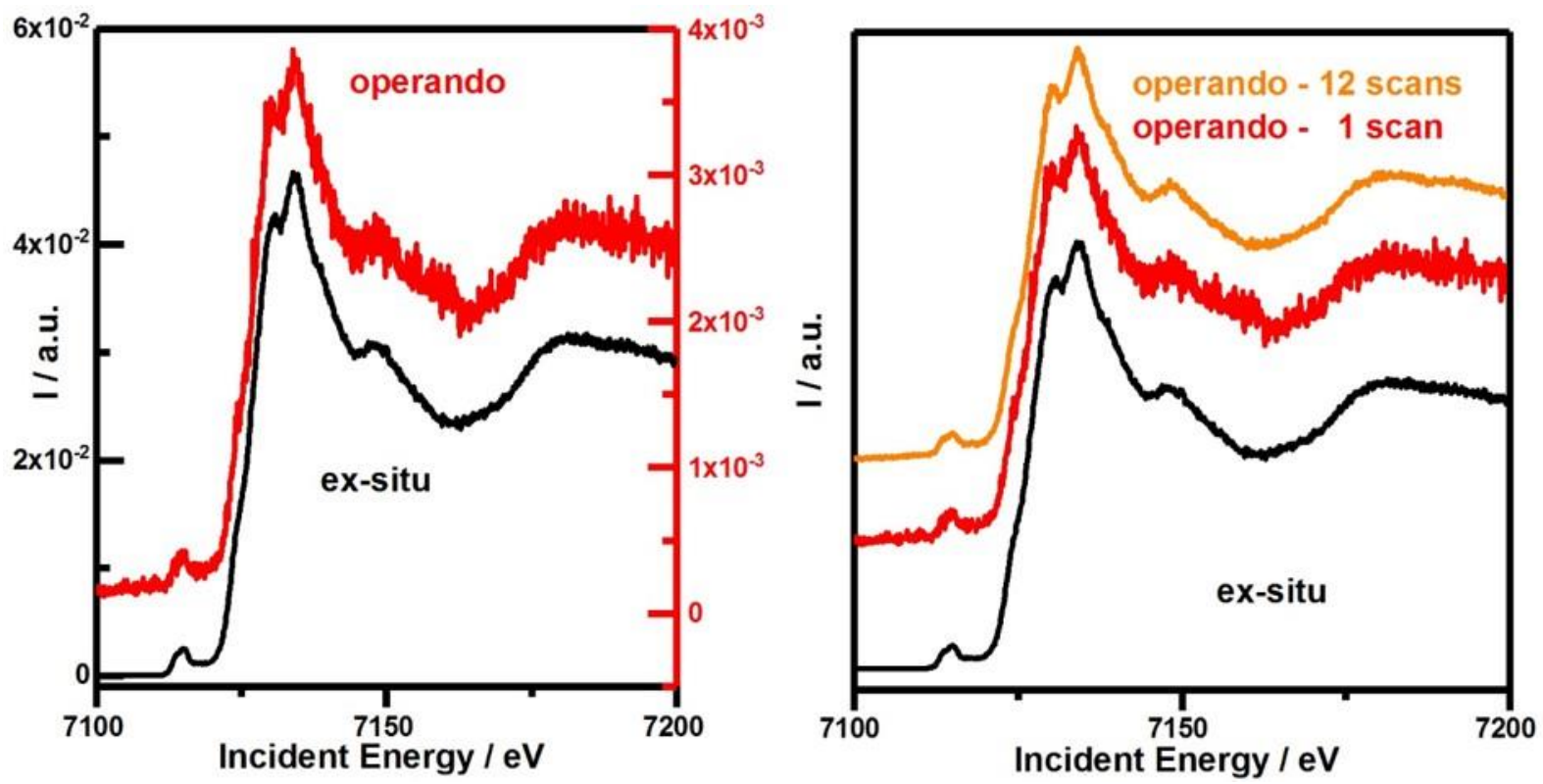

Figure 3. Comparing the quality of $\mathrm{Fe} \mathrm{K}$-edge spectra on $\mathrm{Fe}_{2} \mathrm{O}_{3}$ obtained via $\mathrm{K} \beta$-fluorescence detection under ex situ and operando conditions. The sample was measured under ex situ (black) and operando (red \& orange) conditions. Left: Single scans are recorded for 60 s and normalized to incident beam intensity to compare signal intensity. Right: Scans are normalized to incident beam intensity and spectral area to compare the signal-to-noise ratio $(\mathrm{SNR})$.

To explain the deviation between estimation and experiment we need to consider the beam's spatial profile and the measurement geometry (Figure $4 \mathrm{a}$ ). The intensity loss is a result of the orthogonality between the photon-in and photon-out beam. First, it increases the optical path length inside the electrolyte (Figure $4 \mathrm{~b}$ ) and second it leads to a smaller mutual focal spot of photon-in and photon-out beam (Figure $4 \mathrm{c}$ ). The optical path length is enlarged from $400 \mu \mathrm{m}$ to $566 \mu \mathrm{m}$ which explains a lower detection yield of $18.7 \%$ (SI) but not as low as $8.33 \%$. This difference can be explained considering that the photon-in beam size of $0.8 \mathrm{~mm}(\mathrm{w}) \times 0.1 \mathrm{~mm}(\mathrm{~h})$ yields a greater projected beam size of $1.13 \mathrm{~mm}(\mathrm{w}) \times 0.1 \mathrm{~mm}(\mathrm{~h})$ on the photo-electrode which reduces the average photon flux by 0.707 . Although in principle the spectrometer focus of all 5 crystals $(\sim 1-2 \mathrm{~mm}$, determined from alignment scans) is large enough to cover the area the orthogonal detection geometry (Figure 4 a) allows to cover 
only a width of $\sim 0.4 \mathrm{~mm}$ (Figure $4 \mathrm{c}$ ). This represents a detection yield of $35.4 \%$. In combination with previously determined losses due to the extended optical path length an overall detection yield of $6.6 \%$ is calculated which approximates the experimentally determined $8.33 \%$ detection yield. The SNR of a single operando scan is clearly reduced compared to an ex situ scan (Figure 3, right). However, an average out of 12 operando scans restores the SNR to a level of an individual ex situ scan. Our theoretical estimation seems to capture most essential aspects that cause this decline and thus provides understanding as well as guidelines to optimize the SNR for future operando studies. Moreover, under operando conditions we do not observe X-ray beam damage of the films as shown in Figure S10. Thus, our cell can be directly used at extremely brilliant source (EBS) storage ring like MAX IV, ESRF or after the upgrade of Petra IV at the time scales relevant for photoelectrochemical processes.

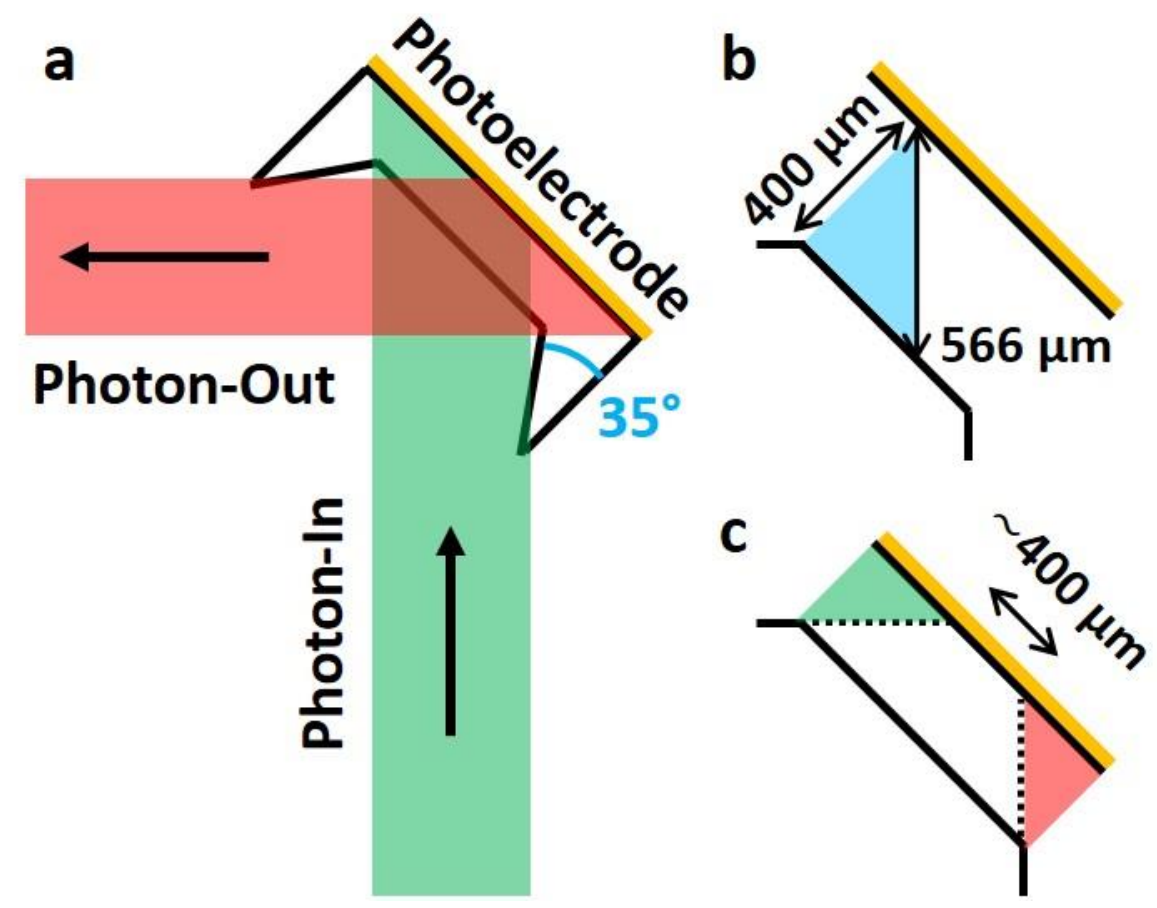

Figure 4. (a) Schematic (top view) illustrating photon-in (incident X-ray, green) and photon-out (fluorescent X-ray, red) beam profiles covering different regions on the photoelectrode (orange). Intensity is collected from a photoelectrode (orange) region where photon-in and photon-out profiles overlap. Profiles are defined through 
incident beam size and crystal spectrometer focus size. (B) Orthogonality between photon-in and photon-out beam prolongs the optical path length in the electrolyte to $566 \mu \mathrm{m}$. (C) The overlapping region of photon-in and photon-out profiles is reduced to approximately $400 \mu \mathrm{m}$.

Finally, we conduct the operando experimental protocol and record HERFD-XAS spectra of hematite, $\mathrm{NiFe}_{2} \mathrm{O}_{4}$ and $\mathrm{ZnFe}_{2} \mathrm{O}_{4}$ (Figure S11) under open-circuit (OC), electrochemical (EC) and photoelectrochemical (PEC) conditions. The Fe K-edge excitation spectra on hematite (Figure S11 a) are recorded via the K $\beta$ fluorescence line $(7059 \mathrm{eV})$ and spectra on $\mathrm{NiFe}_{2} \mathrm{O}_{4}$ and $\mathrm{ZnFe}_{2} \mathrm{O}_{4}$ (Figure $\mathrm{S} 11 \mathrm{~b}-\mathrm{c}$ ) are measured via the Ka fluorescence line $(6405 \mathrm{eV})$ to increase the signal intensity. Note that we also recorded $\mathrm{Ni}$ K-edge spectra on $\mathrm{NiFe}_{2} \mathrm{O}_{4}$ (Figure S1 1 d). Interestingly, despite high quality of the data, at minutes time scale we do not observe any changes under PEC conditions, neither in the pure HERFD-XANES spectra nor in the differential spectra $(\triangle E C$ and $\triangle \mathrm{PEC})$ as shown in Figure S11. However, we demonstrate the general applicability of our cell to measure high-quality (high SNR) HERFD-XAS spectra under photoelectrochemical conditions. Additionally, the experimental conditions can easily be extended towards more intense or pulsed light sources and pump-probe detection schemes to study PEC effects at shorter time scales for example using time-resolved X-ray absorption spectroscopy. ${ }^{44}$

\section{Electrochemical X-ray absorption detection}

The X-ray fluorescence (XRF) that is detected during the experiment is one of many secondary processes that follow the initial X-ray excitation. Additionally, to a radiative decay there are also non-radiative secondary processes that generate electronic or ionic currents, which can be used to measure X-ray absorption spectra. Under applied bias conditions we can distinguish the photoelectrochemical current from the periodically repeated X-ray beam induced current (Figure 5) caused by individual Fe K-edge scans. By zooming into one of 
the respective sections the time-dependent current profile resembles the $\mathrm{X}$-ray absorption profile monitored via fluorescence detection (Figure 5, inset). Since the measured current flows between the thin film photoanode working electrode and platinum wire counter electrode, ionic charge opposed to electronic charge will be carried across the electrolyte in between both electrodes. This has lately been demonstrated as a more bulk-sensitive detection mechanism than total electron yield (TEY) or total fluorescence yield (TFY) and has been named total ion yield (TIY) ${ }^{45,46}$ It might be of use when probing the full depth of $\mu \mathrm{m}$-thick films where redshifted and escaping fluorescent photons are strongly attenuated but electrical current can still be recorded.

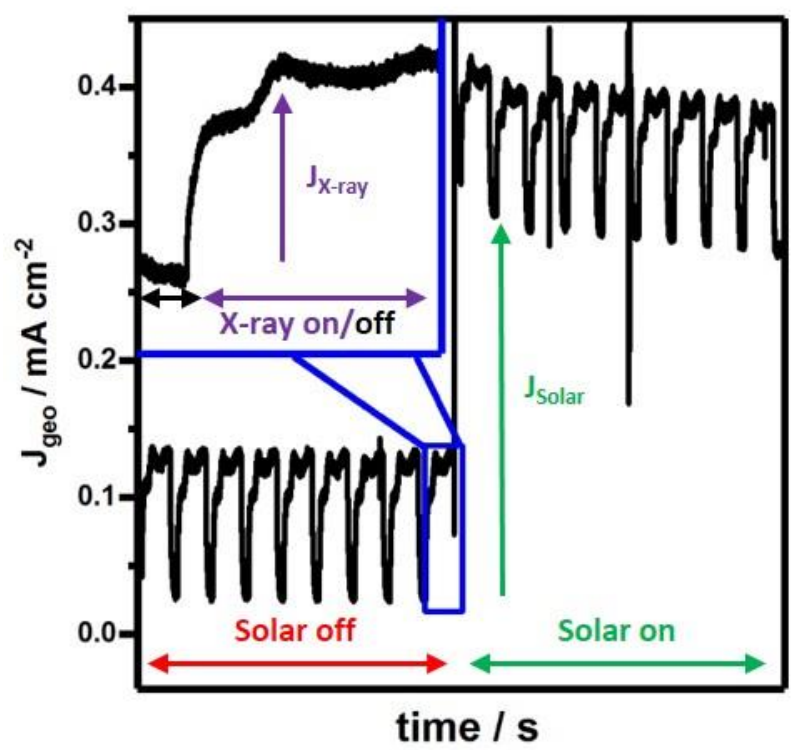

Figure 5. Constant potential photocurrent measurements of $\mathrm{Fe}_{2} \mathrm{O}_{3}$ photoanodes at $1.6 \mathrm{~V}$ vs $\mathrm{RHE}$ recorded in the operando flow cell. (Inset) During HERFD-XAS at the Fe K-edge X-ray exposure induces additional current suitable for ionic-current XAS detection or to examine charge carrier transport properties.

Instead of simply considering the current as a secondary signal that serves to record X-ray absorption spectra, it can also be applied to investigate electronic transport properties using methods that are referred to as photoconduction ${ }^{47}$ or X-ray beam induced current $(\mathrm{XBIC})^{48}$. The latter technique was used to spatially map 
bottlenecks of low minority carrier diffusion length in multicrystalline silicon solar cells caused by metal impurities such as iron ${ }^{49} \mathrm{~A}$ short-wavelength X-ray beam can provide a much smaller illumination cross-section compared to a beam of visible-wavelength light that offers high spatial resolution and element selectivity. Both characteristics have been taken advantage of to visualize and correlate the XBIC with the elemental composition of GaAs across a single nanowire. ${ }^{50}$ These examples illustrate prospective experiments with the operando cell in which electrochemical current detection upon element selective X-ray excitation would allow to determine atom-dependent $\mathrm{X}$-ray beam induced currents such as in multinary oxides, e.g. $\mathrm{ZnFe}_{2} \mathrm{O}_{4}$, or doped semiconductors as for example Ti-doped $\mathrm{Fe}_{2} \mathrm{O}_{3}$. Thus, deeper insights into individual atomic contributions to electronic transport properties would be provided. 


\section{- CONCLUSION \& OUTLOOK}

The operando X-ray absorption spectroscopy approach generally offers insights into device operation but requires sophisticated sample environment. Studying thin films in photoelectrochemical water splitting cells poses obstacles for XAS under working conditions, as many interdependent parameters and functionalities have to be optimized. Our work approaches this challenge based on thorough estimations of radiative transmission leading to an operando HERFD-XAS flow cell in which the electrolyte thickness is reduced to a minimum. Consequently, the cell delivers high transparency for both visible-light $(1.5-3 \mathrm{eV})$ and X-ray $(\geq 6400 \mathrm{eV})$ radiation. The resulting high signal-to-noise ratio enhances the detection limit and minimizes the synchrotron data collection time. Moreover, by reusing a single $\mathrm{Si}_{3} \mathrm{~N}_{4} / \mathrm{Si}$ chip for multiplemeasurements the experimental cost is greatly reduced. PEC current and voltage can routinely be determined and controlled using a standard 3-electrode configuration connected to a commercially available potentiostat that allows to conduct numerous aqueous electrochemical experiments with low electrochemical noise. The high electrochemical and X-ray spectroscopic signal quality are prerequisite to take advantage of the cell's central aspect which is the facile thin film exchange mechanism that relies purely on mechanical fixation. Our approach treats the X-ray transparent window and thin film separately. Thus, the sample can be independently prepared and optimized. This feature made it possible to collect a comprehensive dataset on three different metal-oxide photoelectrodes during a single synchrotron beamtime and can in principal be extended to any desired thin film material. Finally, we describe the potential to electrochemically measure X-ray absorption spectra that might be a suitable detection method for lower X-ray energies. Alternatively, recording the X-ray beam induced current (XBIC) that is element specific might layout atomic contributions to photocurrents, possibly with high spatial resolution using an X-ray microprobe. Overall, this work targets the instrumental bottleneck in operando fluorescence-detected X-ray 
absorption spectroscopy by establishing a measurement routine for experiments on photo- and electrochemical thin film devices, that significantly simplifies the technique's applicability and will stimulate further research.

\section{- AUTHOR INFORMATION}

\section{Corresponding Author}

dorota.koziej@physnet.uni-hamburg.de

\section{Author Contributions}

P.J. wrote the manuscript, conceived all experiments, performed and analyzed PEC, SEM, GIXRD \& XAS experiments, and designed the cell. D.K. acquired funding, supervised the project, revised the manuscript, contributed to the cell design and to the synchrotron experimental planning, performed XAS measurements. T.K. contributed to the cell design and manufactured the cell. D.A. tested and optimized the cell for PEC measurements and assisted during beamtime. R.F. and R.S. produced the thin film samples. R.S. was involved in PEC measurements. B.D. assisted in synchrotron experimental planning and beamline operation.

\section{- ACKNOWLEDGEMENTS}

We acknowledge the European Union for a Marie Curie ITN Grant (Photo4Future, grant number 641861) funded under H2020-EU.1.3.1, ETH Zürich, and University of Hamburg for financial support and European Synchrotron Research Facility (ESRF), ID26 for the beamtime allocation (project number MA-3560). At ETH Zürich, Materials Science Department we thank Prof. M. Niederberger for access to the chemistry lab, materials characterization equipment and helpful discussions, Prof. Andre Studart for access to the SEM, the technical workshop for machining the operando cell. Christoph Willa and Raphael Peltier for assistance during the beamtime. Norcada Inc for $\mathrm{Si}$-embedded $\mathrm{Si}_{3} \mathrm{~N}_{4}$ windows and support in the cell design. PJ thanks Lukas Grote 
and Anke Puchert (Faculty of Physics, University of Hamburg) for helpful scientific discussions, Simon D. Kloß (Ludwig-Maximilians-University of Munich) for proofreading of the manuscript.

\section{EXPERIMENTAL DETAILS}

Chemicals. Acetonitrile (ACN), Sigma-Aldrich, 99.8\%. Benzyl alcohol, Sigma-Aldrich, 99.8\% anhydrous. $\mathrm{CuSO}_{4}$, Sigma-Aldrich, anhydrous, powder, $\geq 99.99 \%$ trace metals basis. Ethanol (EtOH), Sigma-Aldrich, standard for GC. Diethylether $\left(\mathrm{Et}_{2} \mathrm{O}\right)$, Sigma-Aldrich, Laboratory Reagent, $\geq 99.5 \%$ (GC). Isopropanol (IPA), Alfa Aesar, ACS, $\geq 99.5 \%$. 2- 2-(2-methoxyethoxy)ethoxy acetic acid (MEEAA), Sigma-Aldrich, technical grade. NaOH, Sigma-Aldrich, reagent grade, $\geq 98 \%$, pellets (anhydrous). $\mathrm{NH}_{4} \mathrm{OH}$, Sigma-Aldrich, puriss. p.a., reag. ISO, reag. Ph. Eur., $25 \% \mathrm{NH} 3$ basis. Fe(acac) $)_{3}$, Sigma-Aldrich, 97\%. Zn(OAc), Sigma-Aldrich, 99.99\% trace metal basis. $\mathrm{Ni}(\mathrm{OAc})_{2} \times 4 \mathrm{H}_{2} \mathrm{O}$, Sigma-Aldrich, $99.99 \%$ trace metal basis

Nanoparticle synthesis. Ferrite oxide nanoparticles $\left(\mathrm{MFe}_{2} \mathrm{O}_{4}, \mathrm{M}=\mathrm{Zn}, \mathrm{Ni}, \mathrm{Fe}, \mathrm{Co}, \mathrm{Mn}\right)$ are synthesized using a slightly modified benzyl alcohol route. ${ }^{31,32}$ All particles were prepared in $10 \mathrm{~mL}$ benzyl alcohol poured into a $25 \mathrm{ml}$ round-bottom glass flask. To obtain $\mathrm{ZnFe}_{2} \mathrm{O}_{4}$ nanocrystals $1 \mathrm{mmol}(354 \mathrm{mg})$ of Fe(acac) $)_{3}$ and $0.5 \mathrm{mmol}(90 \mathrm{mg})$ of $\mathrm{Zn}(\mathrm{OAc})_{2}$ were used as precursors. $\mathrm{NiFe}_{2} \mathrm{O}_{4}$ nanoparticles (NPs) are produced from $1 \mathrm{mmol}(354 \mathrm{mg})$ of $\mathrm{Fe}(\mathrm{acac})_{3}$ and $0.5 \mathrm{mmol}(125 \mathrm{mg})$ of $\mathrm{Ni}(\mathrm{OAc})_{2} \times 4 \mathrm{H}_{2} \mathrm{O}$. Use of only $1 \mathrm{mmol}(354 \mathrm{mg})$ of $\mathrm{Fe}(\mathrm{acac})$ yield $\mathrm{Fe}_{3} \mathrm{O}_{4}$ NPs that were precursors to form $\mathrm{Fe}_{2} \mathrm{O}_{3}$ NPs upon calcination. All chemicals are stored inside a glovebox under Argon atmosphere. To dissolve precursors in benzyl alcohol the flask is kept at $100^{\circ} \mathrm{C}$ for 2 hours in an oil bath and then transferred to a preheated $220^{\circ} \mathrm{C}$ hot oil bath to avoid the formation of undesired zinc oxides phase. The flask is cooled down to room temperature (RT) and its content is completely poured into a $50 \mathrm{ml}$ centrifuge tube. The flask is rinsed with few $\mathrm{mL}$ of $\mathrm{Et}_{2} \mathrm{O}$ and added to the centrifuge tube. The $\mathrm{Et}_{2} \mathrm{O}$ induces precipitation of the nanoparticles. Centrifugation for $30 \mathrm{~min}$ at $4000 \mathrm{rpm}$ separates the nanoparticles from the liquid. The supernatant 
is discarded and the tube is refilled with $30 \mathrm{ml}$ of a $1: 1$ solution of $\mathrm{EtOH}$ and $\mathrm{Et}_{2} \mathrm{O}$. The sedimented solid residue is whirled up and the tube is centrifuged again for $30 \mathrm{~min}$ at $4000 \mathrm{rpm}$. This process is repeated twice. The solid residue is dried at $60{ }^{\circ} \mathrm{C}$ for 2 hours and finely ground.

Photoelectrode preparation. Photoanode thin films are fabricated from preformed ferrite oxide $\left(\mathrm{MFe}_{2} \mathrm{O}_{4}\right.$, $\mathrm{M}=\mathrm{Zn}, \mathrm{Ni}, \mathrm{Fe}, \mathrm{Co}, \mathrm{Mn}$ ) nanoparticles by spin-coating on fluorine-doped tin oxide (FTO) covered glass substrates $(1.5 \mathrm{~mm} \times 3.5 \mathrm{~mm}, 7 \Omega / \mathrm{sq}$, Solaronix). Prior to use, each FTO substrate is cleaned according to the following procedure. The substrate is consecutively placed into a solution of soap (Migros) water, absolute EtOH and deionised water while being sonicated for $15 \mathrm{~min}$. Afterwards, it is immersed into an IPA solution and dried in a nitrogen stream. The spin-coating solution is prepared by dispersing $60 \mathrm{mg}$ of ferrite nanoparticles in a homogeneous mixture of $940 \mu \mathrm{ACN}, 40 \mu \mathrm{l}$ deionised water and $20 \mu \mathrm{l}$ MEEAA which functions as stabilizer ${ }^{32,51}$ ${ }^{52}$. After sonicating for $30 \mathrm{~min}$ larger agglomerates are removed by filtration to increase the dispersion's (ink) stability with a Chromafil Xtra PTFE-45/25 Syringe Filter from Macherey-Nagel of $450 \mathrm{~nm}$ in pore size. Next, $60 \mu \mathrm{L}$ ink is spin-coated onto FTO for thin film preparation. We employ a WS-650-23NPP Spin Coater from Laurell Technologies to spin the substrate for $30 \mathrm{~s}$ at $4000 \mathrm{rpm}$ in nitrogen atmosphere. Immediately after spincoating the substrates are dried at $300{ }^{\circ} \mathrm{C}$ for 10 min using a pre-heated MR 3004 Safety Hotplate from Heidolph and are let to cool down to RT. Next, the substrates were covered by a ceramic bowl and are heated to $700{ }^{\circ} \mathrm{C}$ at a rate of $10^{\circ} \mathrm{C} \mathrm{min}^{-1}$ for 2 hours in a $R H F 16 / 3 / 3216 P 1$ High-Temperature Box Furnace from Carbolite. The temperature treatment transforms $\mathrm{Fe}_{3} \mathrm{O}_{4}$ into $\mathrm{Fe}_{2} \mathrm{O}_{3}$ nanoparticles whereas $\mathrm{ZnFe}_{2} \mathrm{O}_{4}$ and $\mathrm{NiFe}_{2} \mathrm{O}_{4}$ preserve their crystalline phase. Grazing Incident X-ray diffraction (GIXRD) confirms crystallinity and phase purity as shown in Figure S5. We determine film thickness from cross-sectional scanning electron microscopy images (SEM) to about 50-80 nm exemplary shown for $\mathrm{ZnFe}_{2} \mathrm{O}_{4}$ in Figure $\mathrm{S} 3$. 


\section{Gracing-incidence X-ray diffraction (GIXRD)}

GIXRD experiments of all thin films were conducted with a PANalytical X’Pert Pro producing $\mathrm{Cu}-\mathrm{K}_{1,2}$ radiation that is parallelized using a parabolic W/Si X-ray mirror. The incident beam size is reduced by a $1 / 32^{\circ}$ slit and its intensity is lowered using a $0.125 \mathrm{~mm}$ thick Ni-based programmable beam attenuator. The reflected beam passes a $0.18^{\circ}$ parallel plate collimator and is detected on a Xe-proportionality detector. First, an X-ray reflectivity scan in Omega-2Theta geometry was performed to determine the critical angle of total reflection. Afterwards, a slightly higher fixed incident beam angle at around $0.7^{\circ}$ was chosen for GIXRD measurements in 2 theta geometry.

\section{Scanning electron microscopy (SEM)}

SEM cross-sectional images were taken on a Zeiss Leo 1530 equipped with an in-lens detector. Electrons were accelerated with $3 \mathrm{kV}$ and the beam was scanned across the thin film at a working distance of $4.8 \mathrm{~mm}$.

\section{Photographs}

Optical images of the operando cell and the thin films were taken with a Panasonic DMC FZ200 under variable magnification and exposure time. Contrast and brightness are adjusted using ImageJ.

\section{Crystal structure visualization}

The VESTA program ${ }^{53}$ and was used to visualize the crystal structures. CIF-files of $\mathrm{Fe}_{2} \mathrm{O}_{3}{ }^{54}$ and $\mathrm{ZnFe}_{2} \mathrm{O}_{4}{ }^{55}$ were obtained from the Inorganic Crystal Structure Database (ICSD).

Photoelectrochemical experiments. We produced a $\mathrm{pH} 13.6$ solution by preparing a $1 \mathrm{~mol} \mathrm{~L}^{-1}$ sodium hydroxide electrolyte. The stock solution was prepared by adding $40 \mathrm{~g}$ of $\mathrm{NaOH}$ to $1 \mathrm{~L}$ Milli $-\mathrm{Q}^{\circledR}$ water $(18.2$

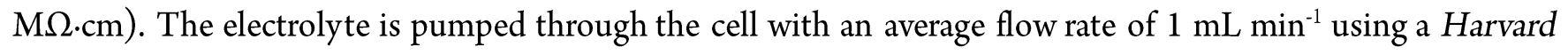
Apparatus PHD ULTRA Syringe Pump. We use $50 \mathrm{~mL}$ plastic syringes and cannulas, $0.8 \mathrm{~mm}$ in diameter that are squeezed into PTFE tubes of $0.7 \mathrm{~mm}$ in diameter. The tubes are connected to the operando cell using flangeless tube end fittings (Vici) that are screwed into M5 threads. 
The electrochemical cell hosts three electrodes in which the FTO substrate serves as working electrode (WE), a $0.5 \mathrm{~mm}$ Pt-wire acts as counter electrode $(\mathrm{CE})$ and a Radiometer $\mathrm{REF} 321(\mathrm{Ag} / \mathrm{AgCl} / \mathrm{KCl} 3 \mathrm{M})$ is the reference electrode (RE). The reference potential of $212 \mathrm{mVvs}$ standard hydrogen electrode (SHE) was converted onto the RHE (reversible hydrogen electrode) scale using the Nernst equation. The three electrodes are electrically connected using clamps. The current-voltage (I-V) experiments were realized using either a BioLogic VMP3 or a portable BioLogic SP-150 potentiostats. A potential range of -2.5 to $+2.5 \mathrm{~V}$ is chosen, resulting in a $100 \mu \mathrm{V}$ resolution. A fixed current range of $1 \mathrm{~mA}$ and a bandwidth factor of 5 is selected. The current average over $0.1 \mathrm{~s}$ is recorded. Solar-like irradiation was provided by an Oriel solar simulator equipped with a $300 \mathrm{~W}$ Xe lamp which light emission was spectrally adjusted to resemble an AM $1.5 \mathrm{G}$ spectrum using a dedicated filter. Light intensity was further reduced with a neutral density filter (Newport, FS-ND) and the PEC cell was placed at a distance that provided a power density of $100 \mathrm{~mW} / \mathrm{cm}^{2}$ previously determined using a calibrated Si-photovoltaic reference cell (Oriel, 91150V). The illuminated surface area on the photoelectrode was $0.280 \mathrm{~cm}^{2}$ and $0.031 \mathrm{~cm}^{2}$ for in-house and operando cell, respectively. For operando experiments an optical fibre was used to direct the light from the solar simulator onto the photoelectrode.

Operando cell. Technical drawings were created using the Autodesk Inventor 2017 software. The cell is machined from poly(methylmethacrylate) (PMMA) and additionally equipped with $\mathrm{Si}_{3} \mathrm{~N}_{4}$ windows. To this end, the two $\mathrm{Si}_{3} \mathrm{~N}_{4}$ membranes $(1.2 \mathrm{~mm}$ (width) x $1.3 \mathrm{~mm}$ (length) x $500 \mathrm{~nm}$ (height)) are embedded into a $15 \mathrm{~mm} \times$ $15 \mathrm{~mm}$ Si-chip (Norcada Inc).

HERFD-XAS. Experiments were carried out at ID26 at the European Synchrotron Research Facility (ESRF) in Grenoble, France. To obtain Fe K-edge X-ray absorption spectra the incident beam was monochromatized using two Si (111) crystals and tuned around the absorption edges of Fe and $\mathrm{Ni}$, at $7112 \mathrm{eV}$ and $8333 \mathrm{eV}$, respectively. The X-ray fluorescence was detected using a wavelength-dispersive Johann-type spectrometer in 
Rowland geometry which operated with 5 spherically bent $\mathrm{Ge}(440), \mathrm{Ge}(620)$ or Si (620) crystals, to selectively reflect and focus $\mathrm{Fe} \mathrm{K \alpha -,} \mathrm{K \beta}$ - or $\mathrm{Ni} \mathrm{K \alpha}$ radiation onto an avalanche photodiode (APD) detector. The total energy resolution given as the FWHM of the elastic peak was $1.3 \mathrm{eV}$ for $\mathrm{Fe} \mathrm{Ka}, 1.4 \mathrm{eV}$ for $\mathrm{Fe} \mathrm{K} \beta$ and $1.6 \mathrm{eV}$ for $\mathrm{Ni} \mathrm{Ka}$. A typical HERFD-XAS scan was measured from $7100 \mathrm{eV}$ to $7200 \mathrm{eV}$ for the Fe K-edge and from $8325 \mathrm{eV}$ to 8414 $\mathrm{eV}$ for the Ni K-edge with a step size of $0.1 \mathrm{eV}$ and a duration of $60 \mathrm{~s}$ per scan. All scans are normalized with respect to the beam intensity, APD dead time and spectrally integrated area using PyMca and OriginLab Pro. To improve the signal-to-noise ratio (SNR) in operando experiments we averaged over 30 scans.

\section{- REFERENCES}

1. Chu, S.; Cui, Y.; Liu, N., The path towards sustainable energy. Nat. Mater. 2017, 16, (1), 16-22. 2. Sivula, K.; van de Krol, R., Semiconducting materials for photoelectrochemical energy conversion. Nat. Rev. Chem. 2016, 1, 15010.

3. Ardo, S.; Fernandez Rivas, D.; Modestino, M. A.; Schulze Greiving, V.; Abdi, F. F.; Alarcon Llado, E.; Artero, V.; Ayers, K.; Battaglia, C.; Becker, J.-P.; Bederak, D.; Berger, A.; Buda, F.; Chinello, E.; Dam, B.; Di Palma, V.; Edvinsson, T.; Fujii, K.; Gardeniers, H.; Geerlings, H.; H. Hashemi, S. M.; Haussener, S.; Houle, F.; Huskens, J.; James, B. D.; Konrad, K.; Kudo, A.; Kunturu, P. P.; Lohse, D.; Mei, B.; Miller, E. L.; Moore, G. F.; Muller, J.; Orchard, K. L.; Rosser, T. E.; Saadi, F. H.; Schüttauf, J.W.; Seger, B.; Sheehan, S. W.; Smith, W. A.; Spurgeon, J.; Tang, M. H.; van de Krol, R.; Vesborg, P. C. K.; Westerik, P., Pathways to electrochemical solar-hydrogen technologies. Energy \& Environmental Science 2018, 11, (10), 2768-2783.

4. $\quad$ Detz, R. J.; Reek, J. N. H.; van der Zwaan, B. C. C., The future of solar fuels: when could they become competitive? Energy \& Environmental Science 2018, 11, (7), 1653-1669.

5. Shaner, M. R.; Atwater, H. A.; Lewis, N. S.; McFarland, E. W., A comparative technoeconomic analysis of renewable hydrogen production using solar energy. Energy \& Environmental Science 2016, 9, (7), 2354-2371.

6. Kim, T. W.; Ping, Y.; Galli, G. A.; Choi, K.-S., Simultaneous enhancements in photon absorption and charge transport of bismuth vanadate photoanodes for solar water splitting. Nat. Commun. 2015, 6.

7. Kim, J. H.; Kim, J. H.; Jang, J. W.; Kim, J. Y.; Choi, S. H.; Magesh, G.; Lee, J.; Lee, J. S., Awakening Solar Water-Splitting Activity of $\mathrm{ZnFe} 2 \mathrm{O} 4$ Nanorods by Hybrid Microwave Annealing. Adv. Energy Mater. 2015, 5, (6), 1401933.

8. Hufnagel, A. G.; Peters, K.; Müller, A.; Scheu, C.; Fattakhova-Rohlfing, D.; Bein, T., Zinc Ferrite Photoanode Nanomorphologies with Favorable Kinetics for Water-Splitting. Adv. Funct. Mater. 2016, 26, (25), 4435-4443.

9. The fine line between performance improvement and device practicality. Nat. Commun. 2018, 9, (1), 5268 .

10. Iqbal, A.; Bevan, K. H., Simultaneously Solving the Photovoltage and Photocurrent at Semiconductor-Liquid Interfaces. J. Phys. Chem. C 2017.

11. Toma, F. M.; Cooper, J. K.; Kunzelmann, V.; McDowell, M. T.; Yu, J.; Larson, D. M.; Borys, N. J.; Abelyan, C.; Beeman, J. W.; Yu, K. M.; Yang, J.; Chen, L.; Shaner, M. R.; Spurgeon, J.; Houle, F. A.; 
Persson, K. A.; Sharp, I. D., Mechanistic insights into chemical and photochemical transformations of bismuth vanadate photoanodes. Nat Commun 2016, 7.

12. Zhang, S.; Rohloff, M.; Kasian, O.; Mingers, A. M.; Mayrhofer, K. J. J.; Fischer, A.; Scheu, C.; Cherevko, S., Dissolution of BiVO4 Photoanodes Revealed by Time-Resolved Measurements under Photoelectrochemical Conditions. J. Phys. Chem. C 2019, 123, (38), 23410-23418.

13. Weckhuysen, B. M., Operando spectroscopy: fundamental and technical aspects of spectroscopy of catalysts under working conditions. Phys. Chem. Chem. Phys. 2003, 5, (20), 1.

14. Singh, J.; Lamberti, C.; van Bokhoven, J. A., Advanced X-ray absorption and emission spectroscopy: in situ catalytic studies. Chem. Soc. Rev. 2010, 39, (12), 4754-4766.

15. Hirsch, O.; Kvashnina, K. O.; Luo, L.; Süess, M. J.; Glatzel, P.; Koziej, D., High-energy resolution X-ray absorption and emission spectroscopy reveals insight into unique selectivity of La-based nanoparticles for CO2. Proceedings of the National Academy of Sciences 2015, 112, (52), 15803-15808. 16. Bergmann, A.; Martinez-Moreno, E.; Teschner, D.; Chernev, P.; Gliech, M.; de Araujo, J. F.; Reier, T.; Dau, H.; Strasser, P., Reversible amorphization and the catalytically active state of crystalline Co3O4 during oxygen evolution. Nat Commun 2015, 6, 8625.

17. Amidani, L.; Naldoni, A.; Malvestuto, M.; Marelli, M.; Glatzel, P.; Dal Santo, V.; Boscherini, F., Probing Long-Lived Plasmonic-Generated Charges in TiO2/Au by High-Resolution X-ray Absorption Spectroscopy. Angew. Chem., Int. Ed. 2015, 54, (18), 5413-5416.

18. Friebel, D.; Louie, M. W.; Bajdich, M.; Sanwald, K. E.; Cai, Y.; Wise, A. M.; Cheng, M.-J.; Sokaras, D.; Weng, T.-C.; Alonso-Mori, R.; Davis, R. C.; Bargar, J. R.; Nørskov, J. K.; Nilsson, A.; Bell, A. T., Identification of Highly Active Fe Sites in (Ni,Fe)OOH for Electrocatalytic Water Splitting. J. Am. Chem. Soc. 2015, 137, (3), 1305-1313.

19. Zhang, Y.; Pelliccione, C. J.; Brady, A. B.; Guo, H.; Smith, P. F.; Liu, P.; Marschilok, A. C.; Takeuchi, K. J.; Takeuchi, E. S., Probing the Li Insertion Mechanism of ZnFe2O4 in Li-Ion Batteries: A Combined X-Ray Diffraction, Extended X-Ray Absorption Fine Structure, and Density Functional Theory Study. Chem. Mater. 2017.

20. Pfeffer, M. G.; Schafer, B.; Smolentsev, G.; Uhlig, J.; Nazarenko, E.; Guthmuller, J.; Kuhnt, C.; Wachtler, M.; Dietzek, B.; Sundstrom, V.; Rau, S., Palladium versus platinum: the metal in the catalytic center of a molecular photocatalyst determines the mechanism of the hydrogen production with visible light. Angew. Chem., Int. Ed. 2015, 54, (17), 5044-8.

21. Yoshida, M.; Yomogida, T.; Mineo, T.; Nitta, K.; Kato, K.; Masuda, T.; Nitani, H.; Abe, H.; Takakusagi, S.; Uruga, T.; Asakura, K.; Uosaki, K.; Kondoh, H., In situ observation of carrier transfer in the Mn-oxide/Nb:SrTiO3 photoelectrode by X-ray absorption spectroscopy. Chem. Commun. 2013, 49, (71), 7848-7850.

22. Minguzzi, A.; Naldoni, A.; Lugaresi, O.; Achilli, E.; D'Acapito, F.; Malara, F.; Locatelli, C.; Vertova, A.; Rondinini, S.; Ghigna, P., Observation of charge transfer cascades in alpha-Fe2O3/IrOx photoanodes by operando X-ray absorption spectroscopy. Phys. Chem. Chem. Phys. 2017, 19, (8), 57155720 .

23. Braun, A.; Sivula, K.; Bora, D. K.; Zhu, J.; Zhang, L.; Grätzel, M.; Guo, J.; Constable, E. C., Direct Observation of Two Electron Holes in a Hematite Photoanode during Photoelectrochemical Water Splitting. J. Phys. Chem. C 2012, 116, (32), 16870-16875.

24. Santomauro, F. G.; Lübcke, A.; Rittmann, J.; Baldini, E.; Ferrer, A.; Silatani, M.; Zimmermann, P.; Grübel, S.; Johnson, J. A.; Mariager, S. O.; Beaud, P.; Grolimund, D.; Borca, C.; Ingold, G.; Johnson, S. L.; Chergui, M., Femtosecond X-ray absorption study of electron localization in photoexcited anatase TiO2. Sci. Rep. 2015, 5, 14834.

25. Achilli, E.; Minguzzi, A.; Visibile, A.; Locatelli, C.; Vertova, A.; Naldoni, A.; Rondinini, S.; Auricchio, F.; Marconi, S.; Fracchia, M.; Ghigna, P., 3D-printed photo-spectroelectrochemical devices 
for in situ and in operando X-ray absorption spectroscopy investigation. J. Synchrotron Rad. 2016, 23, (2), 622-628.

26. Henke, B. L.; Gullikson, E. M.; Davis, J. C., X-Ray Interactions: Photoabsorption, Scattering, Transmission, and Reflection at $\mathrm{E}=50-30,000 \mathrm{eV}, \mathrm{Z}=1-92$. At. Data Nucl. Data Tables 1993, 54, (2), 181-342.

27. Shavorskiy, A.; Ye, X.; Karslıoğlu, O.; Poletayev, A. D.; Hartl, M.; Zegkinoglou, I.; Trotochaud, L.; Nemšák, S.; Schneider, C. M.; Crumlin, E. J.; Axnanda, S.; Liu, Z.; Ross, P. N.; Chueh, W.; Bluhm, H., Direct Mapping of Band Positions in Doped and Undoped Hematite during Photoelectrochemical Water Splitting. J. Phys. Chem. Lett 2017, 5579-5586.

28. Lee, D. K.; Lee, D.; Lumley, M. A.; Choi, K.-S., Progress on ternary oxide-based photoanodes for use in photoelectrochemical cells for solar water splitting. Chem. Soc. Rev. 2019.

29. Zhu, X.; Guijarro, N.; Liu, Y.; Schouwink, P.; Wells Rebekah, A.; Formal, F.; Sun, S.; Gao, C.; Sivula, K., Spinel Structural Disorder Influences Solar-Water-Splitting Performance of ZnFe2O4 Nanorod Photoanodes. Adv. Mater. 2018, 0, (0), 1801612.

30. Dillert, R.; Taffa, D. H.; Wark, M.; Bredow, T.; Bahnemann, D. W., Research Update: Photoelectrochemical water splitting and photocatalytic hydrogen production using ferrites (MFe2O4) under visible light irradiation. APL Mater. 2015, 3, (10), 104001.

31. Kubli, M.; Luo, L.; Bilecka, I.; Niederberger, M., Microwave-assisted nonaqueous sol-gel deposition of different spinel ferrites and barium titanate perovskite thin films. Chimia (Aarau) 2010, 64, (3), 170-2.

32. Zeng, G.; Shi, N.; Hess, M.; Chen, X.; Cheng, W.; Fan, T.; Niederberger, M., A General Method of Fabricating Flexible Spinel-Type Oxide/Reduced Graphene Oxide Nanocomposite Aerogels as Advanced Anodes for Lithium-Ion Batteries. ACS Nano 2015, 9, (4), 4227-4235.

33. Reinhard, S. Nanostructured Tungsten Oxide Photoanodes for Photoelectrochemical Hydrogen Production. Zürich, ETH-Zürich, 2016.

34. Malviya, K. D.; Dotan, H.; Yoon, K. R.; Kim, I.-D.; Rothschild, A., Rigorous substrate cleaning process for reproducible thin film hematite $(\alpha$-Fe2O3) photoanodes. J. Mater. Res. 2015, 31, (11), 15651573 .

35. Maabong, K.; Hu, Y.; Braun, A.; Machatine, A. G. J.; Diale, M., Influence of anodization time on the surface modifications on $\alpha-\mathrm{Fe} 2 \mathrm{O} 3$ photoanode upon anodization. J. Mater. Res. 2016, 31, (11), 15801587.

36. Braun, A.; Chen, Q.; Flak, D.; Fortunato, G.; Gajda-Schrantz, K.; Grätzel, M.; Graule, T.; Guo, J.; Huang, T.-W.; Liu, Z.; Popelo, A. V.; Sivula, K.; Wadati, H.; Wyss, P. P.; Zhang, L.; Zhu, J., Iron Resonant Photoemission Spectroscopy on Anodized Hematite Points to Electron Hole Doping during Anodization. ChemPhysChem 2012, 13, (12), 2937-2944.

37. Bard, A. J., Electrochemical methods : fundamentals and applications. 2nd ed. ed.; New York: Wiley: 2001.

38. Le Formal, F.; Sivula, K.; Grätzel, M., The Transient Photocurrent and Photovoltage Behavior of a Hematite Photoanode under Working Conditions and the Influence of Surface Treatments. J. Phys. Chem. C 2012, 116, (51), 26707-26720.

39. Kenyon, C. N.; Ryba, G. N.; Lewis, N. S., Analysis of time-resolved photocurrent transients at semiconductor/liquid interfaces. The Journal of Physical Chemistry 1993, 97, (49), 12928-12936.

40. Smith, S. W., The Scientist and Engineer's Guide to Digital Signal Processing. 1997.

41. Schroeder, D. J., Astronomical Optics. 2000.

42. Gross, H., Handbook of Optical Systems. 2005, 1.

43. Réfrégier, P., Noise Theory and Application to Physics. 2004.

44. Chergui, M.; Collet, E., Photoinduced Structural Dynamics of Molecular Systems Mapped by Time-Resolved X-ray Methods. Chem. Rev. 2017, 117, (16), 11025-11065. 
45. Schön, D.; Xiao, J.; Golnak, R.; Tesch, M. F.; Winter, B.; Velasco-Velez, J.-J.; Aziz, E. F., Introducing Ionic-Current Detection for X-ray Absorption Spectroscopy in Liquid Cells. J. Phys. Chem. Lett 2017, 8, (9), 2087-2092.

46. Schön, D.; Golnak, R.; Tesch, M. F.; Winter, B.; Velasco-Velez, J.-J.; Aziz, E. F.; Xiao, J., BulkSensitive Detection of the Total Ion Yield for X-ray Absorption Spectroscopy in Liquid Cells. J. Phys. Chem. Lett 2017, 8, (20), 5136-5140.

47. Hu, T. D.; Xie, Y. N.; Qiao, S.; Hai, Y.; Jin, Y. L.; Xian, D. C., Photoconduction extended x-rayabsorption fine structure of GaAs. Phys. Rev. B 1994, 50, (4), 2216-2220.

48. Vyvenko, O. F.; Buonassisi, T.; Istratov, A. A.; Hieslmair, H.; Thompson, A. C.; Schindler, R.; Weber, E. R., X-ray beam induced current-a synchrotron radiation based technique for the in situ analysis of recombination properties and chemical nature of metal clusters in silicon. J. Appl. Phys. 2002, 91, (6), 3614-3617.

49. Buonassisi, T.; Istratov, A. A.; Pickett, M. D.; Marcus, M. A.; Hahn, G.; Riepe, S.; Isenberg, J.; Warta, W.; Willeke, G.; Ciszek, T. F.; Weber, E. R., Quantifying the effect of metal-rich precipitates on minority carrier diffusion length in multicrystalline silicon using synchrotron-based spectrally resolved x-ray beam-induced current. Appl. Phys. Lett. 2005, 87, (4), 044101.

50. Johannes, A.; Salomon, D.; Martinez-Criado, G.; Glaser, M.; Lugstein, A.; Ronning, C., In operando X-ray imaging of nanoscale devices: Composition, valence, and internal electrical fields. Sci. $A d v$. 2017, 3, (12).

51. Grote, C.; Cheema, T. A.; Garnweitner, G., Comparative Study of Ligand Binding during the Postsynthetic Stabilization of Metal Oxide Nanoparticles. Langmuir 2012, 28, (40), 14395-14404.

52. Erdem, D.; Shi, Y.; Heiligtag, F. J.; Kandemir, A. C.; Tervoort, E.; Rupp, J. L. M.; Niederberger, M., Liquid-phase deposition of ferroelectrically switchable nanoparticle-based BaTiO3 films of macroscopically controlled thickness. J. Mater. Chem. C 2015, 3, (38), 9833-9841.

53. Momma, K.; Izumi, F., VESTA 3 for three-dimensional visualization of crystal, volumetric and morphology data. J. Appl. Crystallogr. 2011, 44, (6), 1272-1276.

54. Maslen, E. N.; Streltsov, V. A.; Streltsova, N. R.; Ishizawa, N., Synchrotron X-ray study of the electron density in [alpha]-Fe2O3. Acta Crystallographica Section B 1994, 50, (4), 435-441.

55. Waerenborgh, J. C.; Figueiredo, M. O.; Cabral, J. M. P.; Pereira, L. C. J., Temperature and Composition Dependence of the Cation Distribution in Synthetic ZnFeyAl2-yO4 $(0 \leq \mathrm{y} \leq 1)$ Spinels. Journal of Solid State Chemistry 1994, 111, (2), 300-309. 